\title{
TRANSPARÊNCIA NA GESTÁO PÚBLICA DO BRASIL CONTEMPORANEO: AVANÇOS INSTITUCIONAIS E DESAFIOS ADMINISTRATIVOS
}

\author{
RicARdo Carneiro \\ Fundação João Pinheiro, Brasil \\ ricardo.carneiro@fjp.mg.gov.br
}

\section{RESUMEN}

El acceso a la información de interés público es reconocido como uno de los pilares de la gobernabilidad democrática y una condición para la ciudadanía plena. En Brasil, los principios de publicidad, transparencia y acceso a la información fueron incorporados en la Constitución Federal de 1988, que otorga a los ciudadanos el derecho a recibir información estatal de interés público y privado. No obstante, la materialización de este objetivo político dependía de la regulación a través de la legislación federal, lo que se llevó a cabo apenas recientemente. Subsiste, sin embargo, el reto de equipar la administración pública con el fin de lograr un cumplimiento efectivo de dichas normas jurídicas. El presente artículo examina este tema destacando, por un lado, los innegables avances en el marco normativo y, por otro, las dificultades que enfrentan las autoridades locales para asegurar su observancia.

Palabras clave: Rendición de cuentas, Publicidad, Transparencia, Control social, Brasil. 


\title{
TRANSPARENCY IN PUBLIC ADMINISTRATION IN MODERN BRAZIL: INSTITUTIONAL DEVELOPMENT AND ADMINISTRATIVE CHALLENGES
}

\begin{abstract}
Access to information of public interest is recognized as one of the pillars of democratic governance and a condition for full citizenship. In Brazil, the principles of publicity, transparency and access to information were included in the Federal Constitution of 1988, which provides citizens with the right to receive state information of private and public interest. However, the materialization of this political goal depended on regulation through federal legislation, which was done only recently. The challenge remains, however, of equipping public administration in order to achieve effective compliance of mentioned legal norms. The article examines this issue, highlighting on the one hand, the undeniable advances in the normative framework, and on the other, the difficulties faced by local authorities to ensure its observance.
\end{abstract}

Keywords: Accountability, Publicity, Transparency, Societal control, Brazil. 


\section{INTRODUÇÃO}

O expansionismo do sistema capitalista que toma forma no pós-guerra começa a dar claros sinais de esgotamento na transição dos anos 1960 (Hirschman 1996, Carneiro e Menicucci 2011). A perda do dinamismo econômico cria um ambiente de instabilidade e incertezas que abala a hegemonia entáo conquistada pelo pensamento keynesiano e traz, como subproduto, uma ampla reavaliação do papel adequado para o Estado, sua relação com o mercado e com a sociedade. As ideias liberais readquirem crescente saliência no âmbito desse processo, para influenciarem, sob o rótulo do neoliberalismo, as agendas reformistas que passam a ser progressivamente adotadas em diferentes partes do mundo.

$\mathrm{Na}$ visão que começa a se tornar dominante em meados dos anos 1970, os problemas que grassavam nos países capitalistas centrais foram associados ao Estado e seu padrão de relação com o mercado e a sociedade. No cerne da questão estaria o crescimento excessivo e descontrolado das funções e atividades estatais, levando à ocorrência de déficits públicos sistemáticos e à consequente escalada do estoque da dívida pública. No desdobrar do processo, conforme Carneiro e Menicucci (2011: 10-11), "emergem explicaçóes para o gigantismo do setor público centrados nos limites da democracia liberal em assegurar um controle mais efetivo da sociedade sobre o Estado". Abrem-se aqui duas vertentes principais de abordagem política da crise que estaria acometendo o Estado. A primeira, e mais influente delas, é associada à Nova Direita. Formulado a partir de premissas pluralistas, o argumento dessa vertente interpretativa converge para a proposição da existência de uma sobrecarga no Estado, que teria se tornado hipertrofiado em decorrência do atendimento de demandas a ele canalizadas por múltiplos grupos de interesse da sociedade, onde se incluem interesses incrustrados no próprio aparato governamental (Dunleavy e O'Leary 1987, Held 1987). Esse crescimento desordenado dos gastos públicos refletiria disfunções na operação das instituiçóes democráticas "para a regulamentação eficiente das questóes econômicas e sociais" (Held 1987: 210), estreitando o espaço reservado à iniciativa individual e ao mercado. A segunda vertente aparece associada à Nova Esquerda, sendo formulada a partir de premissas da teoria marxista (Held 1987). Na leitura da Nova Esquerda, a crise do Estado seria de legitimação, refletindo seu comprometimento com os interesses do sistema capitalista de produção (O’Connor 1967, Held 1987, Oliveira 2009). O argumento construído afirma, em síntese, que a instabilidade inerente ao capitalismo torna necessária uma intervenção crescentemente ampliada do Estado com o intuito de manter a "ordem política e econômica das sociedades" (Held 1987: 212), dando sustentação à dinâmica de reprodução ampliada do 
capital.

Em sintonia com a interpretação da Nova Direita, toma forma uma agenda de reforma do Estado que combina a preocupação com a redução das funçôes que este desempenha, envolvendo iniciativas de privatização e de desregulamentação, com "esforços para modernizar e agilizar o funcionamento da administração pública” (Kettl 2005: 75), os quais convergem para a chamada New Public Management (NPM). Já a Nova Esquerda aponta na direçáo do aprofundamento da democracia, colocando ênfase na participação e na deliberação como mecanismos para reformular o modus operandi do Estado, tornando os processos decisórios $\mathrm{e}$ as atividades do governo mais abertos e inclusivos. Percorrendo caminhos distintos, e com enfoques também distintos, tais vertentes interpretativas inscrevem na agenda política a necessidade de reconstrução das relaçóes entre Estado e sociedade, colocando em relevo a noção de accountability, à qual se associam questóes como controle, responsabilização e transparência, dentre outras.

Falar em accountability, aplicada à relação entre Estado e sociedade, por sua vez, implica qualificá-la como democrática, no sentido de que a prevalência da democracia configura-se como uma espécie de pré-requisito para a mesma. Isto se deve ao fato de que a noção de accountability não pode ser dissociada da delegaçáo de poder dos cidadáos para os governantes (Pinho e Sacramento 2009), da qual decorre a concomitante previsão de mecanismos de controle da atividade estatal e de responsabilização pela conduta adotada no exercício da autoridade política. Essa questão assume particular relevância em países da América Latina, como o Brasil, onde a democracia nem sempre é a regra. No caso brasileiro, a restauração da normalidade democrática remete à década de 1980 e tem, como marco referencial, a promulgação da Constituição Federal de 1988 (CF-88).

Consoante a lógica de um sistema democrático, os cidadãos possuem o direito de exercer o controle sobre os atos dos governantes e influenciar a definição da agenda pública, em busca da promoção de seus interesses individuais e coletivos. São aspectos contemplados na CF-88, que promove avanços importantes tanto no que se refere à garantia de acesso à informaçáo quanto no tocante à incorporação de elementos de democracia participativa e deliberativa na gestão pública do país (Brasil et al. 2010). Dirigindo-se a atenção para a questáo do controle societal, sua recepção pelo texto constitucional se evidencia na adoção de princípios como os de publicidade, transparência e acesso à informação. São princípios que fazem, do acesso à informação, não apenas um direito do cidadão, mas um dever do Estado. 
A materialização deste desiderato político, no entanto, ficou pendente de regulamentação e detalhamento operacional por meio de legislaçáo infraconstitucional, o que somente vai tomar corpo a partir da transição para o século XXI. Nessa linha, é possível apontar três importantes marcos legais, a começar da Lei Complementar N. ${ }^{\circ} 101$ - a Lei de Responsabilidade Fiscal (LRF) -, editada em 2000. Por meio dela foram adotadas medidas com vistas a tornar a administraçáo pública mais eficiente e transparente, obrigando os administradores públicos dos diferentes níveis de governoUnião, estados e municípios- a prestar informaçôes relativas à gestão fiscal e a assumir responsabilidades sobre os atos praticados, voltadas a permitir aos cidadãos acompanhar e avaliar a aplicação dos recursos públicos e fiscalizar a conduta daqueles a quem foi confiada a responsabilidade de gerilos. Outro avanço remete a 2009, quando foi editada a Lei Complementar N. ${ }^{\circ} 131$, conhecida como Lei da Transparência, que acrescenta dispositivos à LRF, com o intuito de determinar a disponibilização, em tempo real, de informações sobre a execução financeira e orçamentária dos entes governamentais, em meios eletrônicos de acesso público. Mais recentemente, em 2011, tem-se a edição da Lei N. ${ }^{\circ} 12.527$, rotulada como Lei de Acesso à Informação, que prevê o acesso dos cidadãos a qualquer informação pública, estabelecendo procedimentos com tal finalidade. A referida lei consagra a observância da publicidade como preceito geral e do sigilo como exceção, e determina a obrigatoriedade de divulgação de informações de interesse público tanto por iniciativa própria quanto por solicitação da sociedade. Trata-se de um conjunto de dispositivos normativos que aponta na direção de um governo aberto, suscetível à participação e ao controle societal, colocando na agenda pública do país algo que os governantes, de forma voluntária ou espontânea, não necessariamente se disporiam a fazer. Resta, contudo, o desafio de aparelhar a administração pública com vistas ao efetivo cumprimento das determinaçóes legais, o que nada tem de trivial, notadamente no que se refere à esfera dos governos subnacionais, com destaque para as municipalidades.

O artigo examina a questão, destacando, de um lado, os inegáveis avanços no âmbito normativo e, de outro, as dificuldades defrontadas pelas administraçóes locais quanto a assegurar sua observância. A análise empreendida compreende três seçóes, além desta introdução e das consideraçôes finais. Na primeira seção, discute-se a noção de accountability, colocando em relevo a dimensão do controle pela sociedade. A segunda seção trata dos aspectos normativos relacionados ao controle social no país, destacando três importantes marcos legais instituídos pós CF-88 - a Lei de Responsabilidade Fiscal, a Lei da Transparência e a Lei de Acesso à Informação, acima mencionados. A terceira e última seção explora as dificuldades defrontadas pelo setor público brasileiro, notadamente 
na esfera subnacional de governo, quanto ao efetivo cumprimento dos dispositivos legais atinentes ao controle societal. As consideraçóes finais salientam aspectos centrais do argumento analítico construído.

\section{ACCOUNTABILITY PÚBLICA, CONTROLE E TRANSPARÊNCIA}

A noção de accountability pública, conforme Bovens (2007) revelase "esquiva" ou "escorregadia", no sentido de imprecisa, à medida que acomoda um amplo conjunto de termos correlatos, como controle, responsabilização e obrigação de prestação de contas, dentre outras (CLAD 2000, Pinho e Sacramento 2009), com os quais, de certa, se confunde. No cerne do conceito está a ideia de prestação de contas, seja para fins de justificação e legitimação da conduta, quando é considerada adequada, seja para fins de responsabilização do agente responsável pela mesma, em caso contrário. É o que se pode observar na conceituação adotada pelo Centro Latinoamericano de Administración para el Desarrollo (CLAD). Para a instituição, a acepção original do termo refere-se "al cumplimiento de uma obligación de funcionário público de rendir cuentas, sea a un organismo de control, al parlamento o a la sociedade misma" (CLAD 2000: 329). A abordagem de Campos (1990: 1) adota concepção similar, salientando os limites do controle burocrático, de conformação processual ou procedimental, "para tornar efetiva a responsabilidade de servidores públicos", ou seja, para assegurar uma responsabilidade objetiva (Pinho e Sacramento 2009).

Accountability pode ser entendida como uma "relação social na qual um ator vê-se obrigado a explicar ou justificar sua conduta para algum outro ator relevante" (Bovens 2007: 184). A efetividade dessa relaçáo social, por sua vez, requer o preenchimento de algumas condiçóes sistêmicas que informam e instrumentalizam a conduta dos dois atores centrais à mesma, aquele que presta conta e a quem se presta conta. Aplicada ao âmbito das relaçôes que se estabelecem entre Estado e sociedade ou, mais especificamente, ao exercício da autoridade pública pelos governantes perante os governados, as condiçóes sistêmicas que ancoram a accountability remetem às instituiçóes políticas da democracia, que determinam a obrigação de prestar contas por parte de quem governa, de um lado, e preveem instrumentos e instâncias de fiscalização e de aplicação de sançôes, de outro (O'Donnell 2004). Pode-se dizer que a democracia tende a ser uma mera formalidade se o exercício do poder não se vincular à obrigação de "prestar conta" ao público, por quem o exerce, de seus "atos e omissões, de suas decisóes, políticas, e gastos" (Bovens 2007: 182), acoplada à previsão de sançôes àqueles que violarem as obrigaçóes e deveres públicos na condução da atividade governativa. 
Essa estreita associação entre accountability e democracia é explorada por ampla literatura política (Miguel 2005, Przeworski 2005, O’Donnell 1998, 2004, CLAD 2000, Filgueiras 2011, entre outros). O regime democrático é necessariamente representativo, dada à inviabilidade de se implementar a democracia direta nas amplas e complexas sociedades contemporâneas, o que leva à delegação de poder, mediatizada pela realização de eleiçóes. Disto decorre a separaçáo entre governantes e governados, suscitando riscos da ruptura do vínculo entre a vontade e interesses dos representados e a de seus representantes políticos (Przeworski, Stokes e Marin 2006). $\mathrm{O}$ equilíbrio entre a delegação de poder e o controle de seu exercício é o desafio que se coloca. Para lidar com a questão, as democracias envolvem, para além das eleiçôes, arranjos institucionais direcionados a assegurar uma maior convergência entre a atuação dos governos e os interesses da coletividade, o que está no cerne da noção de accountability.

A accountability enquanto elemento crucial da institucionalidade democrática suscita variadas interpretaçóes, dentre as quais a linha de abordagem seguida por O’Donnell $(1998,2004)$ é uma das mais influentes. A discussão empreendida pelo autor considera que a accountability democrática apresenta uma dupla dimensão: a accountability vertical, focada nas relações de controle entre cidadáos e governantes, e a horizontal, relacionada a controles recíprocos entre entidades de natureza estatal.

A dimensão vertical engloba as ações ou atividades desenvolvidas, individual ou coletivamente, por quem ocupa cargos ou funçôes do Estado, eleitos ou não, os quais devem prestar contas à sociedade (O’Donnell 1998). A relaçáo mais central envolve, de um lado, os políticos que assumem o controle do governo e, de outro, os cidadáos, e tem, como mecanismo básico de controle e fiscalização, as eleiçôes livres e competitivas, realizadas de forma periódica. Por meio das eleiçóes tem-se uma delegação de poder da sociedade aos políticos, atrelada à expectativa de atendimento a reivindicaçóes e demandas sociais que são incorporadas à agenda pública do governo eleito. No entanto, há que se destacar o fato de o processo eleitoral, em si mesmo, náo oferecer instrumentos que obriguem efetivamente os políticos a cumprir a agenda da campanha eleitoral com base na qual foram escolhidos (CLAD 2000). Vale dizer, as eleiçóes permitem apenas um controle periódico da conduta dos eleitos, deixando um relativo vazio no tocante à avaliação e controle de suas ações durante o mandato. Se a população não estiver satisfeita com o desempenho daqueles a quem ela delegou o exercício do poder político, resta trocá-los na próxima eleição (Behn 1998), reafirmando a soberania popular que caracteriza a institucionalidade democrática. Outra relação importante na dimensão vertical é a que se estabelece entre os políticos, 
responsáveis pelas decisões de governo, e os gestores ou servidores públicos, responsáveis pela implementação das decisôes tomadas, na qual o controle e fiscalizaçáo repousam no arranjo organizacional confluente com a burocracia weberiana, onde se destacam o papel das regras formais e da hierarquia. Tem-se aqui o que se denomina como controle interno, realizado no âmbito da própria administração pública, cuja essência é processual ou procedimental.

A dimensão horizontal envolve as relações entre os poderes formalmente constituídos e supóe a existência de agências ou instâncias estatais fiscalizando e controlando umas às outras, por meio de mecanismos consagrados pela literatura sob a designação de cheks and balances ou freios e contrapesos institucionais. Conforme O'Donnell (1998), o foco do controle remete ao que pode ser violado ou qualificado como delituoso, considerando não apenas aspectos relacionados à democracia, mas ao liberalismo e republicanismo. No que se refere à democracia, os aspectos mais centrais têm a ver com a garantia de eleiçóes livres e competitivas, coibindo a ocorrência de fraudes e abuso de poder econômico, de um lado, e assegurando a liberdade de associaçáo e o direito à informação e ao debate de questôes de interesse público, de outro. Quanto ao liberalismo, ganha saliência o respeito às liberdades civis e os direitos individuais delas decorrentes, com a coibiçáo de abusos que os afrontem. Já o republicanismo traz à cena a separação entre a esfera pública e privada, com a exigência de que as autoridades "se sujeitem à lei e/ou deem decisiva prioridade aos interesses públicos, e não aos seus próprios interesses privados" (O’Donnell 1998: 6).

Para O'Donnell (1998), a accountability horizontal não se efetiva sem a existência e adequado funcionamento de agências especializadas revestidas de competência formal para exercer a fiscalizaçáo e o controle de outras agências públicas e de seus gestores, configurando o denominado controle externo da administração pública. A ideia básica que informa a atuação das agências especializadas é a "prevenção e, se necessário, punição" (O’Donnell 1998: 7) de açóes que extravasam os limites de autoridade formalmente definidas dos agentes públicos, em especial os atos que envolvem desvio de recursos ou corrupção. Para que isto se materialize, é necessário que a informação prestada por quem esteja obrigado a fazê-lo seja adequada o suficiente para permitir a avaliação da conduta adotada e o questionamento de sua legitimidade. O’Donnell (1998) acrescenta ainda que o controle não se efetiva com base em agências que atuam de forma isolada, mas a partir de uma rede de agências, onde se destaca o papel dos Tribunais de Contas.

A articulação entre os instrumentos de accountability vertical e 
horizontal fundamenta e ancora não apenas o controle democrático dos governantes pelos cidadáos. Ao contrário, serve também de mecanismo de reforço da integridade da governança pública e de legitimação do exercício do poder, ao inibir ou prevenir a corrupção, o nepotismo e o abuso de poder, além de contribuir para melhorias na performance administrativa, ao impor a justificação da conduta dos gestores e favorecer o aprendizado e o aprimoramento da gestão pública (Bovens 2007). No entanto, para que efetivamente cumpra esses variados papeis, a accountability deve ser dinâmica, no sentido de incorporar novas ideias, valores e tecnologias, em sintonia com a evolução da própria gestão pública e da ampliação dos direitos dos cidadãos. É nessa direção que aponta a noção de accountability societal (Peruzzotti 2012), que enfatiza a atuação de uma mídia independente, dos movimentos sociais, das associaçóes civis e das organizaçóes não governamentais em açóes endereçadas tanto ao controle da conduta dos governantes quanto a influenciar a definição da agenda pública.

Há razoável consenso, na atualidade, de que a democratização do Estado demanda o aprofundamento da accountability, num reconhecimento tácito dos limites dos mecanismos clássicos de controle em assegurar a responsabilidade política dos governantes perante os governados, no tocante à responsividade, legitimidade e eficiência no uso dos recursos públicos consoante os interesses e necessidades da sociedade. Ganha saliência aqui a ideia de transparência, que expressa, segundo Black (1997) o oposto de políticas opacas, na qual não há acesso às decisóes e à forma como são tomadas, nem a informaçóes acerca do que elas representam e o que se ganha ou se perde caso implementadas. De uma perspectiva normativa, a transparência é definida por Moser (2001) como a abertura dos procedimentos e práticas utilizadas no âmbito das entidades da administração pública àqueles que não estão diretamente envolvidos no processo, de forma a demonstrar seu bom funcionamento, o que coloca em relevo a importância de se "ampliar as informaçóes da sociedade acerca das açôes realizadas pelos agentes públicos" (Filgueiras 2011: 72). Isto requer, como ressalta a Organização para a Cooperação e Desenvolvimento Econômico (OCDE 2003), a acessibilidade pública de informaçôes objetivas, confiáveis e relevantes, além de fácil compreensão ao cidadão comum.

Ainda que de inegável relevância no tocante ao aprofundamento da accountability, no sentido de ser "impossível pensar a responsabilidade pública sem que as instituiçóes sejam transparentes para o cidadão" (Filgueiras 2011: 5), ela por si só não esgota o potencial de democratização da relação do Estado com a sociedade. Para além da ampla disponibilidade 
de informaçôes de interesse público, como forma de favorecer a fiscalização e o controle da conduta dos gestores públicos, deve existir a possibilidade de debate e deliberação acerca das açóes e políticas de governo, com o intuito de assegurar que os processos representativos da democracia sejam organizados em condiçóes que observem a "pluralidade de interesses e as diferenças de condição social” (Filgueiras 2011: 84) dos diferentes cidadãos. Isto aponta na direçáo da democracia participativa e deliberativa, que supóe, de um lado, instâncias institucionais de participação, "construídas em uma lógica de deliberação pública e voltadas para a inclusão social e ampliação dos direitos" (Brasil et al. 2010: 2) e, de outro, "a capacidade de compromisso moral dos cidadáos com o bem público" (Filgueiras 2011: 92), congruente com o desiderato político do exercício de uma cidadania plena.

\section{DA LEI DE RESPONSABILIDADE FISCAL À LEI DE ACESSO À INFORMAÇÁO}

O processo de redemocratização brasileiro, que ganha corpo no decorrer da década de 1980, propiciou o incremento e o aprimoramento dos mecanismos de controle, accountability e transparência da gestão pública do país. O ápice desse processo é a promulgação da CF-88, que incorporou "vários mecanismos para a sociedade fiscalizar e cobrar o poder público" (Pó e Abrúcio 2006: 680) e para permitir a participação societária na formulação e avaliação de políticas públicas, notadamente no campo social. Dentre os mecanismos que favorecem e fomentam a participação da sociedade em sua relação com o Estado posicionam-se arranjos institucionais variados, como ouvidorias, consultas, audiências públicas, conselhos, conferências e orçamentos participativos, tendo, como sustentação, princípios e dispositivos instituídos pelo texto constitucional.

Dentre os princípios, destacam-se, como já mencionado, os da publicidade, da transparência e o do acesso à informação. $O$ princípio da publicidade encontra-se explicitamente expresso no artigo 37 da CF-88 e tem, por finalidade, proporcionar maior transparência aos atos praticados pela administração pública, exigindo sua ampla divulgação. É por meio da divulgação oficial dos atos administrativos que a sociedade pode aferir sua adequação e consequente legitimidade. Trata-se, portanto, de requisito inequívoco para a efetividade das atividades de controle da administração pública, em especial no que diz respeito às questóes de natureza fiscal e financeira. Já os princípios da transparência e do direito de acesso à informação encontram-se implícitos no artigo 5 da CF-88. Nele é assegurado a qualquer cidadão o direito de receber dos órgãos públicos "informações de seu interesse particular, ou de interesse coletivo ou geral, [...] ressalvadas aquelas cujo sigilo seja imprescindível à segurança da sociedade e do 
Estado”. São princípios que complementam e reforçam o da publicidade, apontando na direção de uma cidadania ativa, ao assegurar aos cidadãos, acesso a informaçáo pública necessária a que possam participar e interferir, direta ou indiretamente, nas decisóes do poder público que lhes dizem, afetando suas condiçóes de vida. O exercício desse direito se presta tanto ao reforço das açóes de controle, conferindo maior acessibilidade pública à prestação de contas, quanto dos mecanismos institucionais da democracia em aspectos relacionados com a formulação, o acompanhamento e a avaliação das políticas e ações de governo.

No tocante aos dispositivos ou prescriçóes constitucionais, cumpre salientar a obrigação de prestar contas de quem lida com recursos públicos e o direito de acompanhar as ações do poder público por parte da sociedade. A obrigação de prestar contas fica assentada no artigo 70 da CF88 e incide sobre "qualquer pessoa física ou jurídica, pública ou privada, que utilize, arrecade, guarde, gerencie ou administre dinheiros, bens e valores públicos". O direito de denunciar irregularidades ou ilegalidades aos órgãos de controle é assegurado, no artigo 74 da CF-88, a "qualquer cidadão, partido político, associação ou sindicato”. São dispositivos que se inscrevem no marco da accountability como relação social, especificando quem deve prestar contas de sua conduta, de um lado, e alargando o espectro do fórum dos atores com direito de questionar a legalidade ou legitimidade da conduta informada, de outro.

Em consonância com a matriz constitucional, coube a legislaçáo posterior regulamentar e conferir materialidade à transparência enquanto instrumento para o aprimoramento dos mecanismos de controle das decisóes e ações desenvolvidas pelo governo e para a consecução do desiderato político de uma gestáo pública efetivamente democrática. Nessa linha, é possível apontar três marcos institucionais que implicam avanços importantes na direçáo e um governo aberto, suscetível à participação e ao controle social: a Lei de Responsabilidade Fiscal, a Lei da Transparência e a Lei de Acesso à Informação. As duas primeiras foram objeto de lei complementar federal ${ }^{1}$ e tratam de matéria afeta às finanças públicas, motivadas formalmente pela promoção de uma gestão fiscal responsável. Já a terceira, também de iniciativa do governo federal, extravasa a dimensão fiscal, buscando assegurar o acesso do cidadão a informaçóes gerais de interesse público, consoante a premissa de que a transparência é "o principal meio para o exercício do controle direto sobre a administração, além de um instrumento da democracia" (Carneiro e Menicucci 2011: 51).

A Lei de Responsabilidade Fiscal - Lei Complementar N. ${ }^{\circ} 101$, editada

1 A lei complementar destina-se a regulamentar matéria contida no texto constitucional. 
em 4 de maio de 2000 - veio regulamentar o texto constitucional na parte referente a tributação e orçamento, estabelecendo normas gerais de finanças públicas aplicadas ao governos federal e subnacionais - estaduais e municipais -, em consonância com o disposto no artigo 163 da CF-88. A referida lei atende também ao artigo 169, o qual determina a definição de limites para as despesas com pessoal da administraçáo pública - questão que já havia sido objeto da Lei Complementar N. 96/1999, por ela revogada.

Conforme consta do texto da exposição de motivos do projeto de lei enviado pelo governo federal ao Legislativo, a Lei de Responsabilidade Fiscal integra o conjunto de medidas do Programa de Estabilidade Fiscal, lançado em outubro de 1998 pelo governo federal, e que tinha, como objetivo, a redução do déficit público e o controle do estoque da dívida pública, vistos como indispensáveis ao êxito da política de estabilização monetária iniciada em 1995 com o lançamento do Plano Real. A responsabilidade na gestão fiscal, preconizada na lei, supóe a ação planejada e transparente, tendo em perspectiva o equilíbrio das contas públicas, o que envolve uma série de dispositivos referentes ao cumprimento de metas de resultados fiscais, à renúncia de receita, à geração de despesas com pessoal e à contratação de operaçóes de crédito, dentre outros. Por se aplicar não apenas ao governo federal, mas também aos governos subnacionais, tal legislação como salienta Arretche (2012: 48), "fortalece a autoridade da Uniáo sobre estados e municípios", ao regular extensivamente a forma como eles "arrecadam seus impostos exclusivos, implementam as políticas sob sua responsabilidade e gastam seus próprios recursos". Em outras palavras, implica substancial redução da autonomia decisória que havia sido assegurada pela CF-88 aos governos subnacionais no tocante às suas decisôes na área financeira e orçamentária.

Para além dessas implicaçóes, interessa destacar aqui a ênfase conferida à transparência pela Lei de Responsabilidade Fiscal. Em sintonia com o princípio da transparência e do direito de acesso à informação do texto constitucional, a Lei de Responsabilidade Fiscal impóe aos gestores públicos a obrigação de emitir relatórios periódicos de gestão fiscal e de execução orçamentária, dando aos mesmos ampla divulgação, inclusive em meios eletrônicos de acesso público. Dentre os instrumentos de transparência da gestão fiscal especificados na legislação incluem-se os "planos, orçamentos e leis de diretrizes orçamentárias ${ }^{2}$, as prestaçóes de contas e o respectivo

2 A CF-88 redesenhou o modelo formal de planejamento no país, ancorando-o no Plano Plurianual (PPA), o qual se configura como instrumento que baliza a ação governamental e desemboca na programação orçamentária do poder executivo. Com base no PPA, formulado numa perspectiva temporal de quatro anos, o poder executivo elabora a Lei de Diretrizes Orçamentárias (LDO) que, aprovada pelo poder legislativo, orienta a formulação da proposta da Lei Orçamentária Anual (LOA). 
parecer prévio, bem como o Relatório Resumido da Execução Orçamentária e o Relatório de Gestáo Fiscal" (artigo 48). Ao lado disso, cabe registrar a menção explícita, no texto legal, do "incentivo à participação popular e realização de audiências públicas, durante os processos de elaboração e discussão dos planos, leis de diretrizes orçamentárias e orçamentos" (artigo 48) como mecanismo de promoçáo da transparência.

Decorrida quase uma década, a transparência na gestão fiscal instituída pela Lei de Responsabilidade Fiscal foi ampliada com a promulgação, em 27 de maio de 2009, da Lei Complementar N. ${ }^{\circ}$ 131, não sem razão denominada Lei da Transparência. De fato, o novo texto legal acrescentou novos artigos à Lei de Responsabilidade Fiscal e alterou a redação de seu artigo 48, com o intuito de assegurar a disponibilização, em tempo real e em meios eletrônicos de acesso público, de informaçóes pormenorizadas sobre a execução orçamentária e financeira dos diferentes níveis de governo, especificando o conteúdo mínimo daquilo que deve ser informado. Para tanto, foram estabelecidos prazos para o cumprimento da determinação legal, a contar de sua data de publicação - um ano para União, estados, Distrito Federal e municípios com mais de 100.000 habitantes; dois anos, para municípios com população entre 50.000 e 100.000 habitantes; e quatro anos para municípios com população inferior a 50.000 habitantes. A Lei da Transparência preocupou-se também com o enforcement de suas prescriçóes, prevendo, como sanção para o descumprimento de prazos na disponibilizaçáo das informaçóes, a possibilidade de o ente infrator ser impedido de receber transferências voluntárias de recursos, de particular relevância financeira para os governos locais.

A Lei da Transparência determinou ainda a obrigatoriedade de adoção, pelos entes governamentais, de sistema integrado de administração financeira e controle (Freesz 2013), cujo padrão mínimo de qualidade foi especificado no Decreto N. ${ }^{\circ} 7.185$, de 27 de maio de 2010, de iniciativa do governo federal. Pelo mesmo decreto, foi prevista a posterior definição, por ato do governo federal, de requisitos tecnológicos e contábeis a serem cumpridos pelo mencionado sistema, de modo a viabilizar a implantação do denominado Plano de Contas Aplicado ao Setor Público, o qual, por sua vez, deverá permitir a consolidação das contas nacionais, consoante padróes internacionais de contabilidade pública. Publicada em 20 de junho de 2011, a portaria que regulamentou a matéria estipulou prazos distintos para a adoção do Plano de Contas 2012, para União, estados e Distrito Federal; e 2013, para os municípios.

Por fim, a Lei de Acesso à Informação - Lei N. ${ }^{\circ} 12.527$ - foi sancionada pela Presidência da República em 18 de novembro de 2011. A mencionada lei veio dispor sobre os procedimentos a serem observados pela União, 
Distrito Federal, estados e municípios no tocante à garantia do acesso à informação previsto no texto constitucional. Dentre seus pontos principais, cabe salientar a adoção do princípio fundamental de que o acesso à informação é a regra e, o sigilo, a exceção. Vale dizer, excetuadas as informaçóes classificadas formalmente como sigilosas, qualquer cidadão pode ter acesso a documentos e informaçóes produzidas ou custodiadas por órgáos públicos em todas as esferas de governo e nos poderes legislativo e judiciário.

Por sua complexidade, a mencionada lei exigiu regulamentação no âmbito do Executivo Federal, o que se fez por meio do Decreto N. ${ }^{\circ}$ 7.724, de 16 de maio de 2012, que assinala sua efetiva entrada em vigor. O mencionado decreto definiu os procedimentos técnicos e operacionais para a garantia do acesso à informação bem como a classificação de informações sob restrição de acesso (Freesz 2013). A partir da vigência da lei, a administração pública se vê obrigada a divulgar informaçóes à sociedade, tanto por iniciativa própria, o que conforma uma transparência ativa, quanto em resposta a solicitaçóes a ela endereçadas, o que conforma uma transparência passiva.

Esse conjunto de leis representa inegável avanço institucional em direção à ampliaçáo e aprimoramento da accountability democrática no país. No entanto, a aplicaçáo das prescriçóes legais, notadamente no que se refere ao efetivo acesso à informação, defronta-se com dificuldades operacionais para seu cumprimento, principalmente na esfera dos governos locais, tendo em vista a baixa profissionalização de seus aparatos administrativos.

\section{DA PRESCRIÇÁO LEGAL À PRÁTICA ADMINISTRATIVA: OS DESAFIOS IMBRICADOS NO DESIDERATO DA TRANSPARÊNCIA DAS CONTAS PÚBLICAS}

É inegável a importância da disponibilização, para a sociedade, de informaçóes acerca do desenvolvimento da atividade governativa, notadamente no que concerne à elaboração e execução do orçamento público. A transparência quanto às variáveis orçamentárias e financeiras, englobando aspectos relativos tanto ao gasto público - quanto se gasta, com que se gasta, como se gasta - e a seu financiamento - quanto se arrecada, como se arrecada - revela-se indispensável ao exercício de uma cidadania mais ativa. São informaçóes que proporcionam subsídios a que o cidadão possa acompanhar a forma como o recurso mobilizado pelo governo está sendo utilizado, seja para influenciar as decisóes atinentes à formulação e implementação da agenda pública ou para fiscalizar o realizaçáo do gasto, tendo em vista sua qualidade, consoante a noção de accountability anteriormente discutida. 
Como visto na seção anterior, o país dá um importante passo no tocante à transparência nas contas públicas em 2000, com a edição da Lei de Responsabilidade Fiscal. Nela previu-se a publicação de relatórios quadrimestrais relativos à gestáo fiscal e à execução orçamentária, aos quais deveria ser dada publicidade, com o propósito declarado de alcançar a sociedade. No entanto, refletindo a preocupação central da lei quanto ao controle dos gastos públicos, as informaçóes que tais relatórios contemplam, além de apresentadas de forma muito condensada, direcionam o foco para o cumprimento de restriçóes e metas de natureza fiscal por ela impostas, prestando-se principalmente às atividades fiscalizatórias desempenhadas pelos órgáos de controle externo da administração pública, com destaque para os Tribunais de Contas. Tendo em vista esse enfoque dos relatórios, ao qual se soma sua linguagem eminentemente técnica, as informaçóes neles contidas, ainda que disponibilizadas para a sociedade, revelam-se de pouca utilidade para a ampla maioria dos cidadãos.

A Lei da Transparência, promulgada mais de uma década depois, procurou interagir com essa situação, estabelecendo novos meios para assegurar a transparência da gestáo fiscal prescrita na Lei de Responsabilidade Fiscal. Para tanto, determinou a liberação, em tempo real, de informaçóes pormenorizadas sobre as despesas realizadas e as receitas obtidas, com o intuito de permitir "o pleno conhecimento e acompanhamento da sociedade" (Lei Complementar N. 131/2009). São informaçóes que devem ser disponibilizadas em "meios eletrônicos de acesso público" (Lei Complementar N. ${ }^{\circ}$ 131/2009), o que implica, na prática, a criação de "portais da transparência" pelos governos. Num reconhecimento implícito dos diferenciais de capacidade técnica e operacional dos entes governamentais, notadamente na esfera dos governos locais, foram estabelecidos prazos também distintos para o cumprimento da determinação legal, como descrito na seção anterior, que, no caso de municípios com população de até 50.000 habitantes, alcança quatro anos.

É importante observar que a preocupação com a qualidade do gasto nas esferas subnacionais de governo, com destaque para o nível local, é de grande relevância na realidade brasileira, tendo em vista o alargamento das atribuiçôes dos municípios no tocante à formulação e implementação de políticas públicas, notadamente na área social, face à descentralização ocorrida pós CF-88. De fato, a partir de meados dos anos 1990, aprofunda-se no país o movimento "na direção da ampliação do papel das municipalidades na provisão de serviços à população, em consonância com os princípios descentralizantes do novo texto constitucional" (Carneiro e Brasil 2011: 3). Com isto, a prestação de serviços básicos em áreas que afetam diretamente o bem-estar da população, como saúde, saneamento e 
educação, dentre outros, passou a ser realizada de forma dominante pelos governos locais, como atesta sua participaçáo na estrutura dos empregos públicos, que se coloca, na atualidade, acima de $50 \%$ do total (Mattos 2011). O ponto a destacar aqui é que essa descentralização na provisão de serviços, que implica ou exige incremento do gasto, náo se faz acompanhar de concomitante incremento da parcela da receita disponível apropriada pelos municípios. A despeito de a CF-88 ter assegurado competência aos municípios para arrecadar impostos que lhes são próprios, bem como transferências intergovernamentais compulsórias, envolvendo tanto repasses oriundos do governo federal quanto do governo estadual, a participação dos governos locais na estrutura da receita pública nacional encontra-se estabilizada próximo ao patamar de $20 \%$ do total (Carneiro e Brasil 2011).

Essa crescente importância assumida pelos municípios na provisão de serviços à população, pressionando uma capacidade de financiamento que se mantém relativamente estável, joga mais luzes sobre o desafio da profissionalização na administração pública brasileira. Como reconhece a literatura, um dos problemas que a descentralização suscita é a maior dificuldade de recrutar e manter quadros de maior qualificação e capacitação profissional (Pollitt 2007), da qual não escapa a ampla maioria dos governos locais, notadamente aqueles de pequeno porte. E são estes os municípios predominantes no país. De acordo com dados do Instituto Brasileiro de Geografia e Estatística (IBGE), dos 5.565 municípios brasileiros, 22,6\% do total tinham menos de 5.000 habitantes em 2011 e outros 23,2\% do total situavam-se entre 5.000 e 10.000 habitantes. Nada menos que $89,1 \%$ do total apresentavam populaçáo de até 50.000 habitantes naquele ano (IBGE 2011).

Além dessa expressiva participação de municípios de pequeno porte, o desafio da profissionalização no âmbito dos governos locais brasileiros é agudizada por fatores como a persistência de práticas de cunho clientelista e patrimonialista No período que antecede a promulgação da CF-88, o acesso ao serviço público nos diversos níveis de governo, especialmente nos municípios, se fazia, em larga medida, por meio de arranjos políticos e administrativos, que passavam ao largo dos critérios meritocráticos de seleção da burocracia weberiana. Servidores assim recrutados posteriormente eram efetivados nos cargos, como integrantes do quadro permanente. Ainda que o texto constitucional tenha prescrito a realizaçáo de concursos para a contratação de pessoal para administração pública brasileira, o preceito, mesmo quando observado pelos municípios, nem sempre envolve processos seletivos abertos e universais, assumindo, com frequência, caráter interno, o qual permite efetivar servidores não concursados que já trabalhavam na 
administração municipal.

Esse baixo grau de profissionalização dos governos locais se insinua na presença relativamente expressiva de duas categorias de trabalhadores - os ocupantes de cargo comissionado e os empregados sem vínculo permanente - na estrutura de ocupação dos municípios. O cargo em comissão é destinado precipuamente ao preenchimento das funçôes de alta direção da administração pública. No entanto, sua elevada participação na estrutura do emprego das administraçóes municipais, da ordem de $8,7 \%$ do total em 2011 (IBGE 2011), sinaliza na direção de contratações que extravasam as atividades de direção ou mesmo de assessoramento especializado, configurando-se como instrumento de barganha e apoio político pelos gestores locais, de conotação clientelista ou particularista. Já os empregos sem vínculo permanente, por sua vez, são justificados usualmente pela característica de "sazonalidade e do horizonte finito da demanda por diversos serviços públicos" (Marconi 2010: 232). Em 2011, representaram $16,1 \%$ do total (IBGE 2011), revelando-se, portanto, prática corriqueira nos governos locais, cuja adoção, vale registrar, permite contornar a exigência de realizaçáo de concurso público. Ainda que a contratação de trabalhadores temporários possa levar em consideração o preenchimento das habilidades técnicas requeridas no desempenho da atividade em questão, a ausência de vínculo permanente é um aspecto que por si só torna mais precária a relação de trabalho, na contramáo de propósitos voltados à profissionalização do serviço público. É sintomático o fato de tal tipo de ocupação ocorrer principalmente nas áreas de apoio administrativo, que se revelam mais favoráveis a "esquemas de patronagem e clientelismo" (Carvalho 2011: 304), por sua baixa exigência de qualificação profissional.

Outra evidência do baixo grau de profissionalização é a prevalência, na esfera dos governos locais, de servidores com formação restrita ao ensino fundamental e médio, que somavam 59,6\% do total dos trabalhadores contratados pelas administraçóes municipais em 2011 (IBGE 2011). $\mathrm{Na}$ explicação do fenômeno aparecem os baixos níveis salariais praticados (Marconi 2010), o que se reflete na capacidade de recrutar e reter trabalhadores com nível mais elevado de escolaridade. A isto se soma um fator restritivo de natureza administrativa, representado pela "ausência de planos de carreira para as principais áreas da administração pública municipal” (Carneiro e Brasil 2011: 15), o que, inegavelmente, desestimula iniciativas de qualificação ou capacitação como forma de avanço profissional e melhoria de remuneração.

A carência de profissionais qualificados, que incide inclusive em áreas estruturais da administração pública, como a gestão fiscal, tende a ser suprida, em parte, pela contrataçáo de serviços de empresas especializadas, 
numa terceirização "forçada", que não guarda relação com a busca de melhoria da performance gerencial. $\mathrm{O}$ recurso à contratação de serviços de terceiros contempla a execução de atividades tipicamente estatais, como a elaboração de orçamentos e a prestação de contas, onde se incluem os relatórios prescritos pela Lei de Responsabilidade Fiscal.

Não surpreende, assim, que os municípios venham encontrando dificuldades na observância da obrigatoriedade de divulgar, em tempo real, informaçóes sobre suas receitas e despesas, conforme preconizado na Lei da Transparência. O estado de Minas Gerais, com seus 853 municípios $^{3}$, ilustra bem a questão, como mostram os dados da Tabela 1, construída com base em levantamento realizado pelo Tribunal de Contas do Estado de Minas Gerais (TCEMG), no âmbito de sua Política de Fiscalização Integrada ${ }^{4}$. Tal levantamento foi feito por meio da web, no período entre setembro de 2012 e janeiro de 2013 , com o intuito de conhecer a situação dos diversos municípios quanto ao cumprimento da mencionada lei. $\mathrm{O}$ resultado foi publicado pelo TCEMG em abril de 2013.

Tabela 1: Número de municípios que cumprem a Lei de Transparência em Minas Gerais, classificados por tamanho da populaçáo, em 2013

$\begin{array}{cccc}\begin{array}{c}\text { Classe de tamanho } \\ \text { (habitantes) }\end{array} & \begin{array}{c}\text { Quantitativo de } \\ \text { municípios }\end{array} & \begin{array}{c}\text { Quantitativo dos } \\ \text { que cumprem a lei }\end{array} & \begin{array}{c}\text { Porcentagem do } \\ \text { total }\end{array} \\ \text { Até 50.000 } & 787 & 564 & 71,6 \\ \text { De 50.000 a 100.000 } & 37 & 35 & 94,6 \\ \text { Acima de 100.000 } & 29 & 29 & 100,0 \\ \text { Total } & 853 & 628 & 73,6\end{array}$

Fonte: Elaboração do autor, com base em dados disponibilizados pelo Tribunal de Contas de Minas Gerais (2013).

De acordo com os dados do levantamento feito pelo TCEMG, pouco antes de vencer o prazo para que todos os municípios se ajustassem à Lei da Transparência - mais especificamente, 28 de maio de 2013 - apenas $73,6 \%$ dos municípios mineiros já estavam publicando, em portais da transparência, informaçóes sobre receitas e despesas exigidas pela legislação. $\mathrm{O}$ não cumprimento incidia principalmente nos municípios com população de até 50.000 habitantes que, como visto, tiveram quatro anos

3 Minas Gerais é o estado brasileiro com maior número de municípios, congregando $15,3 \%$ do total existente no país.

4 A Política de Fiscalização Integrada do TCEMG foi instituída por meio da Resolução N. ${ }^{\circ} 10$, de 22 de junho de 2011, e ganha solidez com a criação, em 2013, de uma unidade técnica para responsabilizar-se por sua operacionalização, a Assessoria para a Coordenaçáo da Fiscalização Integrada. 
para atender a prescrição legal. A despeito desse prazo relativamente longo para a adaptação e do risco de aplicação de sançóes pelo náo cumprimento, sob a forma de suspensão do repasse de transferências intergovernamentais de natureza voluntária, somente $71,6 \%$ dos municípios inscritos na faixa de até 50.000 habitantes já cumpriam o dispositivo legal por ocasião do mencionado levantamento.

É oportuno ressaltar ademais que o fato de publicar informaçôes sobre as contas públicas em site - seja ele próprio (*.mg.gov.br), comercial (*.com.br) ou hospedeiro - não diz nada acerca da qualidade e adequação da informação disponibilizada. A esse respeito, cabe observar que a Lei da Transparência determina que as informaçóes a serem divulgadas envolvam todos os órgáos e entidades do executivo municipal, bem como o poder legislativo. Considerando, para fins ilustrativos, os municípios mineiros de maior porte - com população acima de 50.000 habitantes -, que presumidamente dispóem de maior capacidade burocrática, o levantamento realizado pelo TCEMG mostrou que apenas 34 deles, ou $51,5 \%$ do total, cumpriam a determinação legal. Em outras palavras, embora a quase totalidade de municípios mineiros que se inscrevem na faixa de populaçáo acima de 50.000, 97,0\% do total, disponibilizassem informações sobre suas receitas e despesas, parcela expressiva o fazia de forma apenas parcial, sem contemplar os diversos órgãos do executivo ou o legislativo municipal.

O cenário mostra-se ainda mais adverso no tocante ao cumprimento da Lei de Acesso à Informação, mais exigente de capacidade técnica e gerencial para seu cumprimento, comparativamente à Lei da Transparência. De fato, como visto na seção anterior, a mencionada lei não apenas alarga o escopo das informaçôes que devem ser disponibilizadas pela administração pública, mas as obriga a atender solicitações de informação advindas da sociedade. Ao portal da transparência, decorrente das imposições da Lei da Transparência, vem se somar a necessidade de instituir serviços de informação ao cidadão, por força da Lei de Acesso à Informação.

Por suas exigências no tocante a capacidade institucional, envolvendo aspectos financeiros, tecnológicos e de recursos humanos, a Lei de Acesso à Informação tem se defrontado com dificuldades muito mais agudas de cumprimento pelo poder público que aquelas impostas pela Lei da Transparência. É o que revela levantamento realizado pela Controladoria Geral da União (CGU) - órgáo de controle interno do governo federal. De acordo com dados disponibilizados pelo órgão, referentes a abril de 2013, apenas $54 \%$ dos estados brasileiros haviam regulamentado a lei com vistas à sua aplicação; em fevereiro de 2014, sete estados, correspondendo a $25,9 \%$ do total, persistiam sem a regulamentar. No caso dos municípios, 
a regulamentação era ainda mais restrita, alcançando tão somente $13 \%$ do total em 2013.

A despeito de não constituir o único óbice ao cumprimento da lei, o baixo grau de profissionalização das burocracias públicas nos níveis subnacionais de governo, notadamente nos municípios, não pode ser negligenciado. É o que depreende dos resultados alcançados pelo Programa Brasil Transparente, de iniciativa da CGU, que visa apoiar a administração pública, nos diferentes níveis de governo, a cumprir as prescrições da referida lei. Tal programa envolve um elenco de açóes que combinam desde a cessão de um sistema eletrônico para a prestação de informações à sociedade - uma solução tecnológica denominada e-SIC -, junto com apoio técnico à sua implantação, à elaboração e distribuição de material didático e orientativo sobre a matéria, passando por atividades de capacitação cursos, treinamentos, outros - e assessoria no desenvolvimento de portais da transparência na internet. Lançado em janeiro de 2013, o programa contou, até o final do mês de junho, com a adesão de tão somente 633 municípios, ou $11,4 \%$ do total. No entanto, no que se refere às açôes de capacitação, o quantitativo de municípios envolvidos cai para apenas 160 municípios, ou 2,9\% do total (CGU 2013). Ainda que em caráter especulativo, pode-se supor que o interesse relativamente baixo que vem sendo demonstrado pelos governos locais no tocante às açôes de capacitação promovida pela CGU tenha a ver com dificuldades na indicação de servidores com qualificação suficiente para absorver o conhecimento técnico repassado nos cursos ou treinamentos e posteriormente aplicá-lo. A propósito da questão, existiam, em 2009, apenas 6.249 profissionais e técnicos de informática no conjunto das administraçóes municipais do país (Nogueira e Cardoso Jr. 2011), o que dá uma média de 1,1 profissional por município.

Os avanços normativos no tocante à transparência, portanto, não têm sido acompanhados pelo aparelhamento da administração pública atendêlos. E a atuação dos órgãos de controle, seja por meio de açôes de fiscalização ou de apoio técnico, vem se revelando insuficiente para lidar com a questão, até porque esbarra num problema de natureza estrutural - a fragilidade da capacidade operacional das burocracias públicas, especialmente na esfera local de governo -, de difícil resolução no curto ou médio prazo.

\section{CONCLUSÓES}

A Lei da Transparência e, mais recentemente, a Lei de Acesso à Informaçáo instrumentalizam, inegavelmente, o aprofundamento da democracia no país, criando condições mais favoráveis à participação da sociedade na condução da atividade governativa, consoante as noçôes de accountability vertical e horizontal. Na dimensão vertical, a disponibilidade de informaçôes 
relevantes e oportunas acerca dos processos decisórios relativos à alocação dos recursos públicos é condição indispensável à avaliaçáo das prioridades de governo e da qualidade do gasto pelos cidadáos, potencializando o incremento da participação e o debate informado nos diversos fóruns existentes, como os conselhos de políticas setoriais, as conferências, as audiências públicas, os orçamentos participativos, dentre outros. $\mathrm{Na}$ dimensão horizontal, a observância da publicidade como preceito geral e do sigilo como exceção, alargando o espectro da divulgação de informaçôes de interesse público, contribui para o exercício mais efetivo do controle societal da administração pública, em articulação com as instituiçóes de controle interno e externo - as Controladorias, os Tribunais de Contas e o Ministério Público -, onde se destaca o papel das ouvidorias.

Essa política de incremento à transparência demanda e força a profissionalização da administração pública. Não há como produzir, sistematizar, armazenar e divulgar, de forma tempestiva, informaçóes relevantes à sociedade, sem a existência de capacidade burocrática para fazê-lo. No entanto, capacidade burocrática não se cria por decreto. A construção das condiçôes operacionais que assegurem a eficiência e a efetividade na gestão da informação, compatível com as prescriçóes legais, exige não apenas recursos financeiros, mas também disposição política do governante. Assim, concretizar a transparência mantém-se um desafio em aberto, notadamente na esfera dos governos locais, na qual se observa expressivo número de municípios de pequeno porte, insuficientemente aparelhados para o adequado desempenho de suas atribuiçóes, o que inclui determinaçóes legais, cumpridas, em várias circunstâncias, apenas de forma cerimonial ou ritualística.

No entanto, sem negligenciar as dificuldades na adequação da administração pública às normas legais relativas à transparência, os avanços nesta direção, por parciais que sejam, trazem ganhos que extravasam os aspectos relativos à accountability. A necessidade de produzir e sistematizar informaçóes relativas à gestão pública, decorrente dos dispositivos legais, é do interesse da própria administração pública, já que informação constitui insumo estratégico a qualquer processo racional de tomada de decisóes. Assim, ainda que de forma indireta, o esforço na direção da transparência potencializa a melhoria do processo decisório dos gestores públicos, tornando-o mais informado.

Para o incremento da capacidade de processar informaçóes na esfera dos municípios, contudo, há que se avançar além de açóes de apoio por parte dos níveis mais centrais de governo, especialmente a União, e dos órgáos de controle e fiscalização, como os Tribunais de Contas e as Controladorias. Esforços mais consistentes dos governos locais nessa 
direção parecem demandar o efetivo enforcement das normas instituídas, com a especificação de um órgão de âmbito nacional fiscalizá-las e fazê-las cumprir. 


\section{REFERÊNCIAS}

Arretche, M. T. S. (2012). Democracia, Federalismo e Centralização no Brasil. Rio de Janeiro: Editora FGV.

Behn, R. (1998). O Novo Paradigma da Administração Pública e a Busca da Accountability Democrática. Revista do Serviço Público, 49 (4), 5-45.

Black, J. (1997). Transparent Policy Measures. Em Black, J., Hashimzade, N. e Myles, G (Eds.), Oxford Dictionary of Economics. Oxford: Oxford University Press.

Brasil, F. P. D; Carneiro, R., França, B. C. e Almeida, M. E. (2010). As instâncias locais de participação nas políticas urbanas: uma análise dos desenhos institucionais. Artigo apresentado no Seminário Política e Planejamento, 4 a 6 de agosto, Curitiba, Brasil.

Bovens, M. (2007). Public Accountability. Em Ferlie, E., Lynn Jr., L. E., Pollitt, C. (Eds.), The Oxford Handbook of Public Management. New York: Oxford University Press.

Campos, A. M. (1990). Accountability: Quando Poderemos Traduzi-la para o Português? Revista de Administração Pública, 24(2), 30-50.

Carneiro, R. e Brasil, F. P. D. (2011). Democratização, Descentralização e os Desafios da Governança Local: A Experiência Brasileira Contemporânea. Artigo apresentado no XVI Congreso Internacional del CLAD sobre la Reforma del Estado y de la Administración Pública, 8 a 11 de novembro, Asunción, Paraguay.

Carneiro, R. e Menicucci, T. M. G. (2011). Gestão Pública no Século XXI: As Reformas Pendentes. Brasília: IPEA.

Carvalho, E. D. P. (2011). Emprego Público e Ocupaçóes no Serviço Público Municipal nos Anos 2000. Em Cardoso Júnior, J. C. (Orgs.), Burocracia e Ocupação no Setor Público Brasileiro. Rio de Janeiro: IPEA.

Centro Latinoamericano de Administración para el Desarrollo (CLAD). (2000). La Responsabilización en la Nueva Gestión Pública Latinoamericana. Buenos Aires: Editorial Universitária de Buenos Aires.

Dunleavy, P. e O'Leary, B. (1987). Theories of State: The Politics of Liberal Democracy. London: MacMillan. .

Filgueiras, F. B. (2011). Além Da Transparência: Accountability e Política da Publicidade. Lua Nova, 84, 353-364. 
Freesz, L. A. S. (2013). Lei de Responsabilidade Fiscal: A Evolução da Transparência Fiscal em Belo Horizonte Após a Lei Complementar n. 131/2009. Tese (Mestrado), Fundação João Pinheiro, Belo Horizonte, Brasil.

Held, D. (1987). Modelos de Democracia. Belo Horizonte: Ed. Paidéia.

Hirschman, A. O. (1996). Auto-Subversão: Teorias Consagradas em Xeque. São Paulo: Companhia das Letras.

Instituto Brasileiro de Geografia e Estatística (IBGE). (2011). Pesquisas de Informaçôes Básicas Municipais 2009 e 2011. Rio de Janeiro: IBGE.

Kettl, D. F. (2005). A Revolução Global: Reforma da Administração do Setor Público. Em Bresser-Pereira, L. C. e Spink, P. (Orgs.), Reforma do Estado e Administração Pública Gerencial. Rio de Janeiro: Editora FGV.

Marconi, N. (2010). Uma Radiografia do Emprego Público no Brasil: Análise e Sugestóes de Políticas. Em Loureiro, M. R., Abrucio, F. L. e Pacheco, R. S. (Orgs.), Burocracia e Politica no Brasil: Desafios para o Estado Democrático no Século XXI. Rio de Janeiro: Editora FGV.

Mattos, F. A. M. (2011). Emprego Público no Brasil: Aspectos Históricos e Evolução Recente. Em Cardoso Júnior, J. C. (Org.), Burocracia e Ocupação no Setor Público Brasileiro. Rio de Janeiro: IPEA.

Miguel, L. F. (2005). Impassses da Accountability: Dilemas e Alternativas da Representação Política. Revista de Sociologia e Politica, 25, 25-38.

Moser, C. (2001). How Open is 'Open as Possible?' Three Different Approaches to Transparency and Openness in Regulation to EU Documents. Viena: Institute for Advanced Studies.

Nogueira, R. P. e Cardoso Jr., J. C. (2011). Tendências e Problemas da Ocupação no Setor Público Brasileiro: Conclusóes Parciais e Recomendacóes de Pesquisa. Em Cardoso Jr., J. C. (Org.), Burocracia e Ocupação no Setor Público Brasileiro. Rio de Janeiro: IPEA.

O'Connor, J. (1967). The Fiscal Crisis of State. New York: St. Martin.

O’Donnell, G. (2004). Accountability Horizontal: La Institucionalización Legal de la Desconfianza Política. Revista Española de Ciencia Política, $11,11-31$. 44, 27-54.

(1998). Accountability Horizontal e Novas Poliarquias. Lua Nova, 
Oliveira, F. A. (2009). Economia e Política das Finanças Públicas no Brasil. São Paulo: Hucitec.

Organização de Cooperação e Desenvolvimento Econômico (OCDE). (2003). Public Sector Transparency and International Investment Policy. Paris: OCDE.

Peruzzotti, E. (2012). Accountability Social na América Latina. Em http:// www.lasociedadcivil.org/uploads/ciberteca/accountability_socialIII_ Forum.pdf [01-06-2014.

Pinho, J. A. G. e Sacramento, A. R. S. (2009). Accountability: Já Podemos Traduzi-la para o Português? Revista de Administração Pública, 43 (6), $1343-1368$.

Pó, M. V. e Abrucio, F. L. (2006). Desenho e Funcionamento dos Mecanismos de Controle e Accountability das Agências Reguladoras Brasileiras: Semelhanças e Diferenças. Revista de Administração Pública, 40 (4), 679-698.

Pollitt, C. (2007). Decentralization. Em Ferlie, E., Lynn Jr., L. E. e Pollitt, C. (Eds.), The Oxford Handbook of Public Management. New York: Oxford University Press.

Przeworski, A. (2005). Sobre o Desenho do Estado: Uma Perspectiva Agente x Principal. Em Bresser-Pereira, L. C. e Spink, P. (Orgs.), Reforma do Estado e Administração Pública Gerencial. Rio de Janeiro: Editora FGV.

Przeworski, A., Manin, B. e Stokes, S. C. (2006). Eleiçóes e representação. Lua Nova, n. 67, p. 105-136.

Tribunal de Contas do Estado de Minas Gerais (TCEMG). (2013). Matéria Extrapauta. Diário Oficial de Contas do Tribunal de Contas do Estado de Minas Gerais, 3 de abril. Belo Horizonte: TCEMG.

\section{Sites web}

Controladoria Geral da União: http://www.cgu.gov.br/ PrevencaodaCorrupcao/BrasilTransparente/Servicos/index.asp [03-072013]

Recibido: 11-03-2014

Aceptación de la versión final: 28-06-2014 